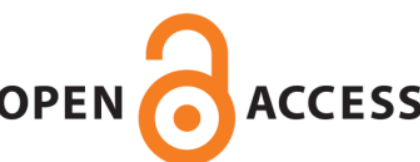

UWS Academic Portal

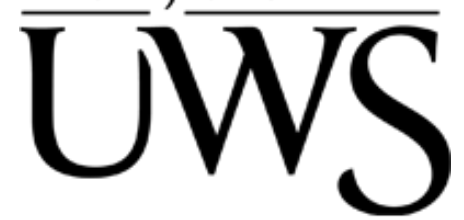

\title{
Effect of shielding gas and energy input rate on the surface geometry and microstructure of a microalloyed steel surface melted with a TIG torch \\ Munoz De Escalona, Patricia; Mridha, Shahjahan; Baker, Thomas
}

Published in:

Advances in Materials and Processing Technologies

DOI:

$10.1080 / 2374068 X .2017 .1350021$

E-pub ahead of print: 10/07/2017

Document Version

Peer reviewed version

Link to publication on the UWS Academic Portal

Citation for published version (APA):

Munoz De Escalona, P., Mridha, S., \& Baker, T. (2017). Effect of shielding gas and energy input rate on the surface geometry and microstructure of a microalloyed steel surface melted with a TIG torch. Advances in Materials and Processing Technologies. https://doi.org/10.1080/2374068X.2017.1350021

\section{General rights}

Copyright and moral rights for the publications made accessible in the UWS Academic Portal are retained by the authors and/or other copyright owners and it is a condition of accessing publications that users recognise and abide by the legal requirements associated with these rights. 


\title{
Effect of shielding gas and energy input rate on the surface geometry and microstructure of a microalloyed steel surface melted with a TIG torch
}

\author{
P. Muñoz de Escalona ${ }^{* 1}$, S. Mridha ${ }^{2}$ and T. N. Baker ${ }^{2}$ \\ ${ }^{1}$ School of Engineering and Computing \\ University of the West of Scotland, \\ Paisley, PA1 2BE, UK. \\ ${ }^{2}$ Department of Mechanical and Aerospace Engineering \\ University of Strathclyde, \\ Glasgow G1 1XJ, UK. \\ "Corresponding author:p.munoz@uws.ac.uk
}

\begin{abstract}
Surface engineering techniques are used to enhance surface properties, such as wear, erosion and/or corrosion of materials, by developing a functionally graded metal matrix composite layer. Recently, as an economic alternative to laser processing, a tungsten inert gas torch has been used to incorporate ceramic particles into a metal surface. This produced about $1 \mu \mathrm{m}$ depth melted and resolidified track on the surface, which during processing, required protection by from oxygen and hydrogen environment, by a shielding gas. The present study analysed the effect of three shielding gases argon, helium, and nitrogen, on the melt zone morphology, microstructure and hardness after melting a microalloyed steel surface under different energy input conditions. The aim was to determine the optimum conditions for future research related to surface engineering, incorporating ceramic particles. The results show that when protected by argon and using energy inputs $<420 \mathrm{~J} / \mathrm{mm}$, an increase of $5 \%$ in the temperature between the start and finish of the melted track was recorded, but this increased to $\sim 25 \%$ when using energy inputs $>420 \mathrm{~J} / \mathrm{mm}$. It was also found, that compared to nitrogen, using argon and helium, a re-solidified homogeneous and consistent cross- section developed along the melted track.
\end{abstract}

Keywords: Surface engineering, TIG, argon shielding gas, microhardness determination, energy input . 


\section{Introduction}

Surface engineering techniques are used to enhance surface properties, such as wear, erosion and corrosion of materials. This allows the surface to perform functions that are distinct from those demanded by the bulk material [1]. For structural engineering applications where the surfaces will be in moving contact, it is recommended that the surface microstructure is modified to a depth $\geq 1 \mathrm{~mm}$. This can be achieved by a melting process provided by a high energy source, such as a laser [2-6] or a TIG torch [7-10]. Molten surfaces must be protected from the atmosphere by shielding gases. In welding, oxygen, nitrogen and hydrogen are prevented from solution and chemical reaction with the melt, by shielding gases such as carbon dioxide, argon or helium, singly or in combination [11]. In laser surface engineering, nitriding is a common technique, where the flow of gas over the molten surface is controlled [12-14]. However, in non-nitriding laser surface engineering, which includes cladding or incorporation of ceramic particulates, with the aim of developing a functional graded surface, region, protection of the melt is normally by argon and/ or helium [4, 12, 13, 15] An alternative, cheaper option to lasers for the surface modification, is a TIG torch technique, which has been shown to be suitable, initially for titanium alloys [8,16-18] and more recently, steels $[19,20]$.

In techniques where the melting occurs along a track, such as in laser or TIG surface engineering, the heat generated by the source is normally conducted to the substrate ahead of the torch, and has been described as 'preheat'. This leads to a gradually higher substrate temperature, resulting in different cooling rates between the start to the finish of a melted surface track, [21]. While 'preheat' has been recognized as affecting the cooling rates during solidification of the molten pool and in the heat affected zone following welding, it has received little attention in surface engineering utilizing lasers or TIG. Furthermore, inhomogeneity in the microstructure, due to 'preheat', is rarely considered in the published literature.

The present work builds on a previous study, [22] which compared the influence the shielding gases argon, helium and nitrogen, and recently [23] for one level of energy input, $\sim 840 \mathrm{~J} / \mathrm{mm}$, obtained from a TIG torch melting a single track in a steel surface. Here, the effect of shielding gases under a range of energy inputs is considered, as a precursor to incorporating ceramic particles to create a functionally graded metal matrix composite layer.

\section{Experimental Procedure}

\subsection{Workpiece characteristics}

Microalloyed steel, with a composition of $0.1 \mathrm{C}-0.7 \mathrm{Mn}-0.05 \mathrm{Cu}-0.05 \mathrm{Nb}$ (all wt. \%), in the form of plates $300 \times 30 \times 10 \mathrm{~mm}$, was used in this study. The chemical composition of the microalloyed steel substrate was determined using a Glow Discharge Optical Emission Spectrometer model Horiba GD-OES profilometer. 
Three holes, of $1 \mathrm{~mm}$ diameter and $5 \mathrm{~mm}$ depth, were drilled from the underside of the substrate, and type $\mathrm{K}$ thermocouples inserted to record the temperature during the melting process. The distribution of the drilled holes divided the melted track into four sections of 75 $\mathrm{mm}$ each, as shown in Figure 1. Once the melting process was completed, the samples were allowed to cool at room temperature for microstructural analysis and microhardness determination.

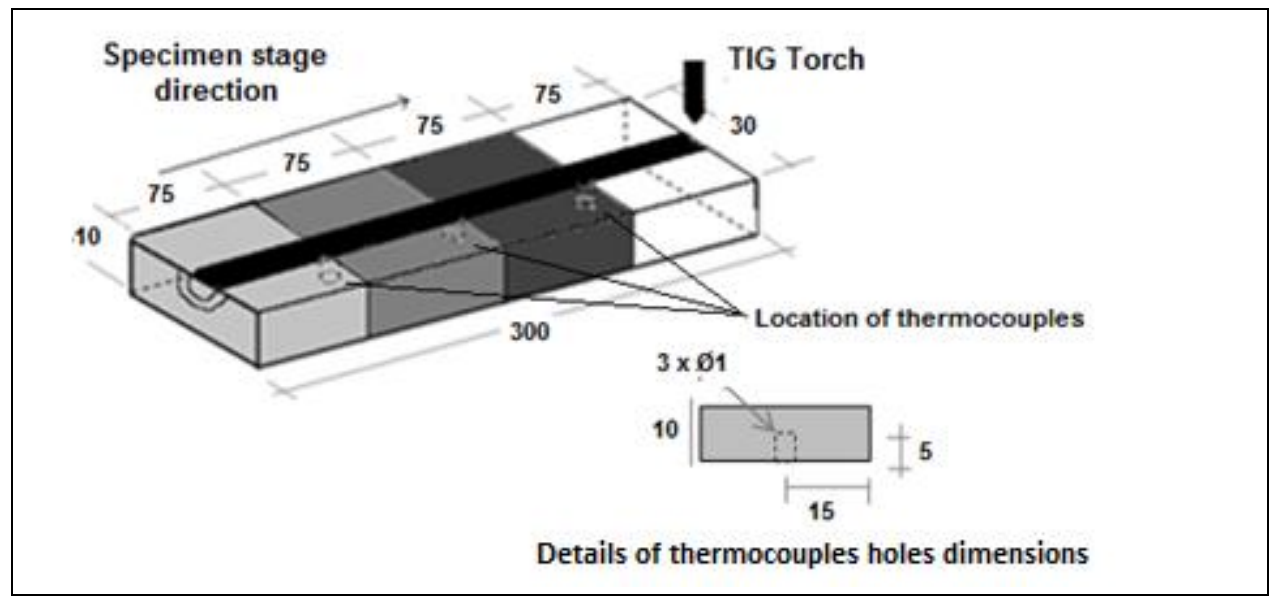

Figure 1 Schematic of the sample dimensions and location of thermocouples along the melted track

To reveal the parent microstructure and that produced by the melting process at 75, 150 and $225 \mathrm{~mm}$ along the re-solidified track, metallography was conducted following ASTM E3-01 standard. Figure 2 shows the banded microstructure of the parent microalloyed steel, where ferrite grains (white zone) and pearlite regions (dark zone) can be observed. As expected, the amount of pearlite is smaller than ferrite, reflecting the carbon content of the steel.

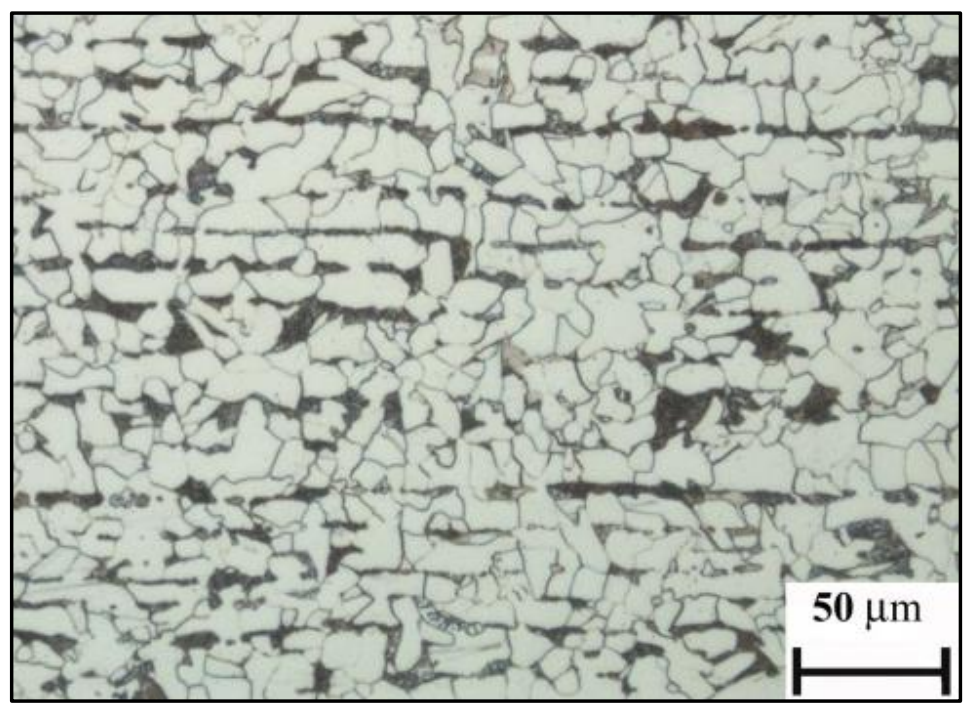

Figure 2. Microstructure of the parent material. Light grains are ferrite, dark region is pearlite 
The microhardness measurements were conducted using a Mitutoyo MVK G1 microhardness tester with 200gf and 15s delay and followed the procedures set out in BS6507-1 1998 and BS 1043-2 1993. Figure 3 shows the pattern used to take the hardness readings on the specimen cross-section, of the melt or fusion zone (FZ), heat affected zone (HAZ) and parent material (PM), starting at $0.1 \mathrm{~mm}$ from the fusion zone surface, and taking measurements in a vertical distance at $0.2 \mathrm{~mm}$ apart towards the centre of PM.

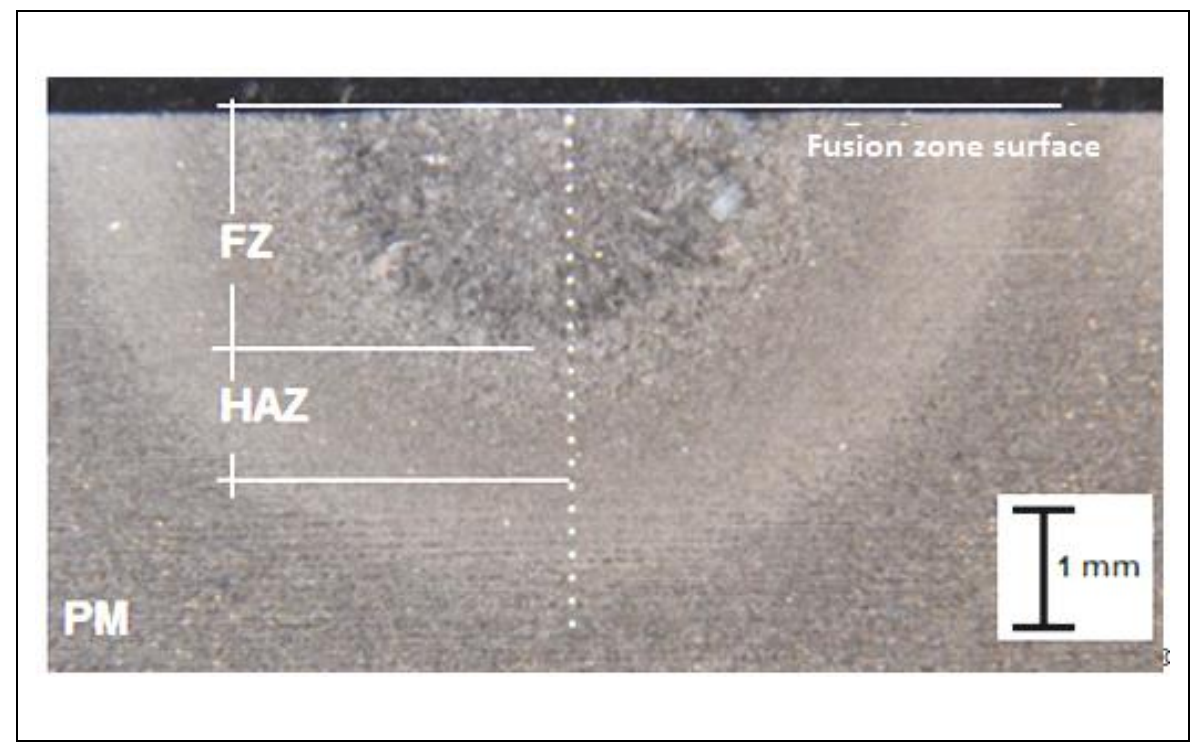

Figure 3. Pattern of indents taken on cross- sectional area of melted track.

First indentation taken at $0.1 \mathrm{~mm}$ from the fusion zone (FZ) edge and $0.2 \mathrm{~mm}$ apart towards the parent material

\subsection{Shielding gases characteristics}

The thermal properties of the three different shielding gases used for the experiments, are collected in Table 1

Table 1. Thermal properties and density of the shielding gases used in this research

\begin{tabular}{lccc}
\hline \multicolumn{1}{c}{ Property } & Argon & Nitrogen & Helium \\
\hline Density $\left[\mathrm{Kg} / \mathrm{m}^{3}\right]$ & 1.62 & 1.17 & 0.17 \\
\hline Specific heat $[\mathrm{kJ} / \mathrm{Kg} \mathrm{K}]$ & 0.52 & 1.04 & 5.19 \\
\hline Thermal conductivity $[\mathrm{W} / \mathrm{m} \mathrm{K}]$ & 0.02 & 0.03 & 0.14 \\
\hline First ionization potential $[\mathrm{eV}]$ & 15.80 & 14.50 & 24.58 \\
\hline
\end{tabular}

Argon, with its low ionization potential, promotes easy arc starting and stable arc operation. However, its lower thermal conductivity promotes the development of axial spray transfer in some forms of Gas Metal Arc Welding (GMAW). Helium, because of its high thermal conductivity and high ionization potential, transfers more heat to the base material, thus enhancing the penetration characteristics of the arc, and for the same energy input produces deeper and wider welds than argon. This can allow faster welding velocities to be used, thus counteracting the higher cost of the gas. [22].The respective generalized weld cross sections 
are seen in Figure 4. It is apparent from Table 1, that nitrogen, which is avoided in welding but is important in laser surface engineering, [4,12-14] has properties closer to argon than helium.

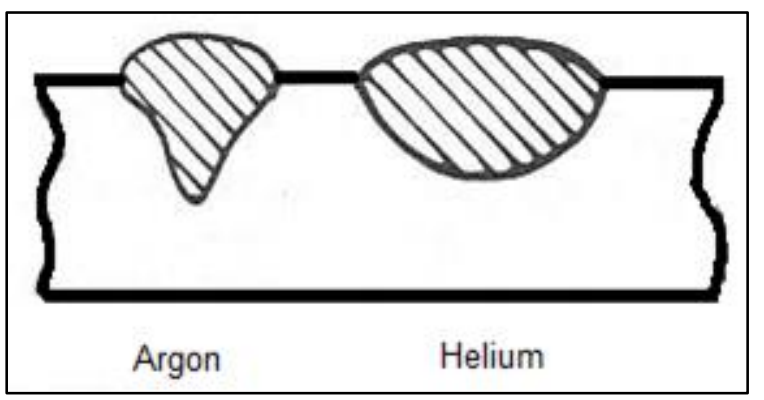

Figure 4. Schematic drawing on weld cross sectional areas when using different shielding gasses (Adapted from ref.[11])

\subsection{TIG Equipment characteristics}

A Miller Dynastry 300DX TIG equipment with a $2.4 \mathrm{~mm}$ diameter thoriated tungsten electrode was used to generate an arc The tungsten electrode was direct current negative and the tip of the electrode was placed $1 \mathrm{~mm}$ above the sample surface

\subsection{Melting conditions and temperature registration}

Different energy input conditions were obtained by varying the combination of the welding parameters. The energy input was calculated using Eq. 1.

$$
\mathrm{E}=\eta \mathrm{VI} / \mathrm{s}
$$

where $\eta$ is the efficiency of energy absorption, or arc efficiency, which was taken as $0.48 \pm$ 0.03 for a TIG process $[24,25]$

Table 2 shows the different heat input values used. For Helium, the lowest values were limited by the arc stability.

Table 2. Energy input values

\begin{tabular}{cc}
\hline Shielding gas & $\mathbf{E}[\mathbf{J} / \mathbf{m m}]$ \\
\hline \multirow{3}{*}{ Argon } & 210 \\
& 420 \\
& 840 \\
\hline Nitrogen & 385 \\
& 840 \\
\hline & 650 \\
Helium & 840 \\
\hline
\end{tabular}




\section{Results and Discussion}

Figure 5 shows the maximum temperature registered by each thermocouple under different energy inputs.

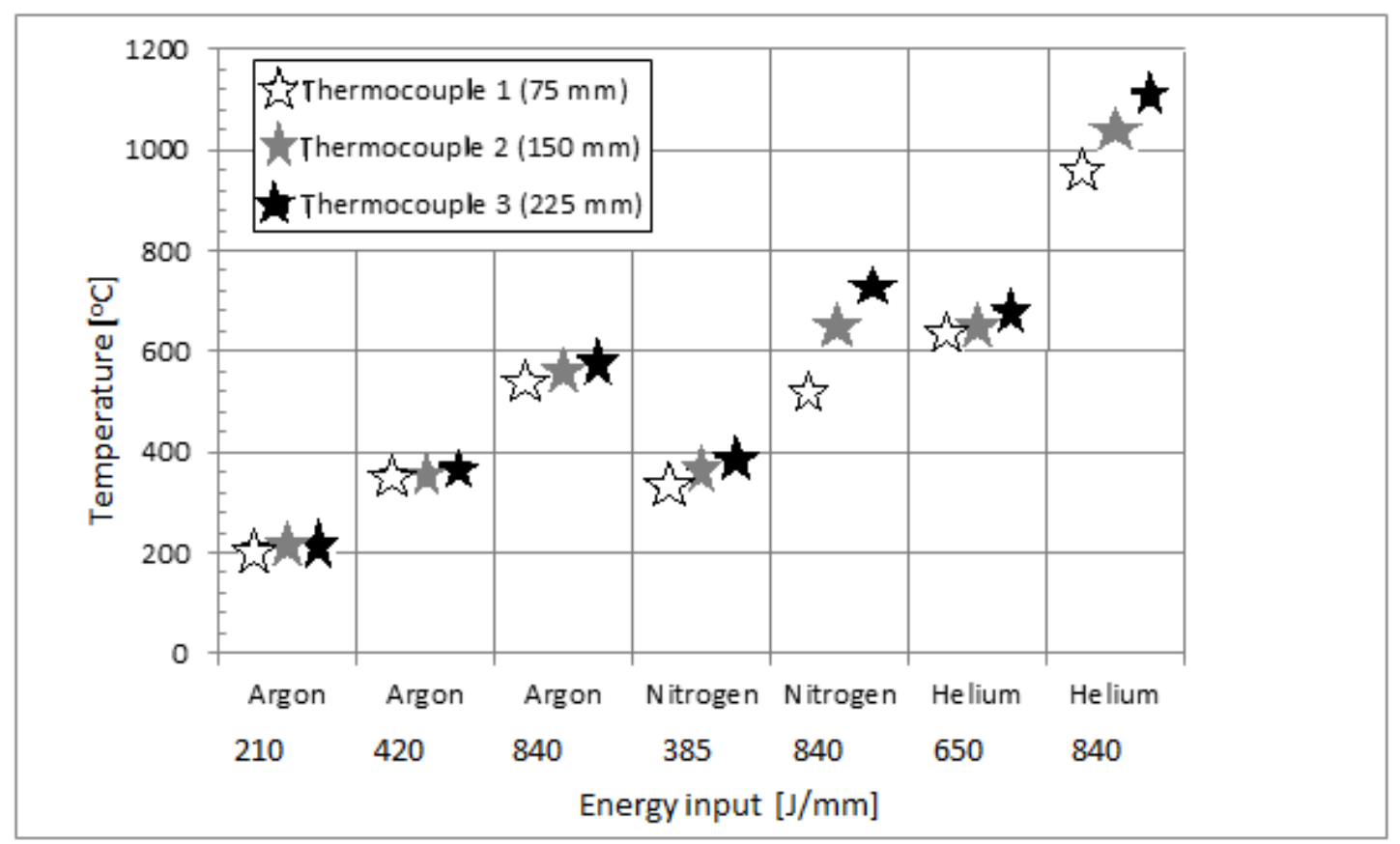

Figure 5. Maximum values of temperature registered by each thermocouple located at different positions along the melted track

The temperatures recorded by the three thermocouples, which are $\sim 4 \mathrm{~mm}$ below the molten zone/HAZ interface, provide relative data only. As observed in Figure 5, for all the samples a higher temperature was recorded by thermocouple 3, $225 \mathrm{~mm}$ along the melted track. This was due to the preheating process to which the samples were subjected during melting [2022]. Also, it is observed that a more noticeable change in maximum temperature occurs between the value registered by the first and third thermocouples respectively, when using nitrogen or helium compared with argon, at energy input rate of $\sim 840 \mathrm{~J} / \mathrm{mm}$. This result is associated with the smaller values of specific heat and thermal conductivity for argon, Table 1. Also, the higher temperatures recorded using helium are associated with the high values of thermal conductivity and the high ionization potential, Table 1, which develop a hotter and boarder arc, conducting to give a deeper and wider fusion zone, Figure 4.This results in a slower cooling of the sample, which means that a coarser microstructure should be obtained when reaching room temperature.

Analysing the data after shielding with nitrogen, it is observed that increasing the energy input from $385 \mathrm{~J} / \mathrm{mm}$ to $840 \mathrm{~J} / \mathrm{mm}(\sim 120 \%)$, resulted in the maximum temperature, increasing by almost $85 \%$, from $395{ }^{\circ} \mathrm{C}$ to $740{ }^{\circ} \mathrm{C}$. The corresponding figures for argon show that an increase of $100 \%$ in the energy input (from $210 \mathrm{~J} / \mathrm{mm}$ to $420 \mathrm{~J} / \mathrm{mm}$ and from 
$420 \mathrm{~J} / \mathrm{mm}$ to $840 \mathrm{~J} / \mathrm{mm}$ ) produced an increase in the maximum temperature of $65 \%$ (from $230{ }^{\circ} \mathrm{C}$ to $380{ }^{\circ} \mathrm{C}$ ) and $55 \%$ (from $380{ }^{\circ} \mathrm{C}$ to $590{ }^{\circ} \mathrm{C}$ ) respectively. This smaller increase in temperature, despite the greater increase in energy input, is associated with the arc stability, which is promoted by the low ionization potential of this gas, Table 1 . The results obtained for argon are in agreement with those of Patel et al [22], despite the difference in the geometry of the samples, $50 \mathrm{~mm}$ in length, compared to $300 \mathrm{~mm}$ used in this research.

Figure 6 shows an increase in the fusion zone geometry (depth and width) with energy input. It can be seen that the behaviour of nitrogen when using an energy input rate of $\sim 840 \mathrm{~J} / \mathrm{mm}$, is observed to produce a fusion zone on average, $45 \%$ wider and $100 \%$ deeper compared to argon, while the corresponding figures for helium are $85 \%$ and $90 \%$. These results are again associated with the high values of ionization potential and specific heat of the helium, determining the conduction of heat outward from the core of the melted zone.

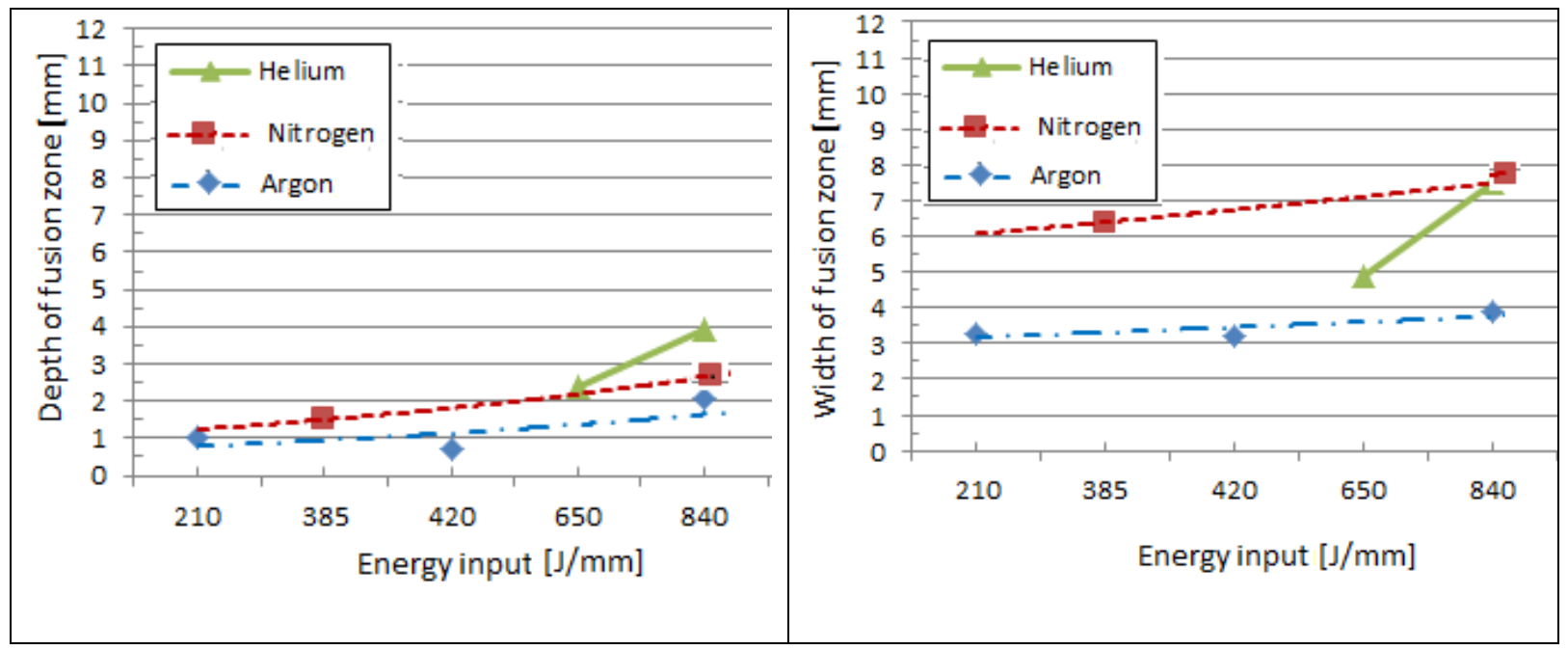

Figure 6. Influence of the heat input on melted zone geometry

a) depth of FZ and b) width of FZ, for different shielding gases

Figure 7 shows macrographs of the melt pool cross- sectional areas as well as the respective values of areas of the fusion zone (dash red lines), at two distances along the melted track. As observed when analysing Figure 7, in general, a homogeneous appearance of the melted pool cross-sectional area along the melted track was seen using argon and helium as a shielding gas. Tewari et al [26] found similar results using argon. However, a very irregular surface of the melted track was obtained for nitrogen after $75 \mathrm{~mm}$, changing to a smoother surface after $225 \mathrm{~mm}$ sample. This was especially the case when using an energy input rate of $\sim 840 \mathrm{~J} / \mathrm{mm}$. 


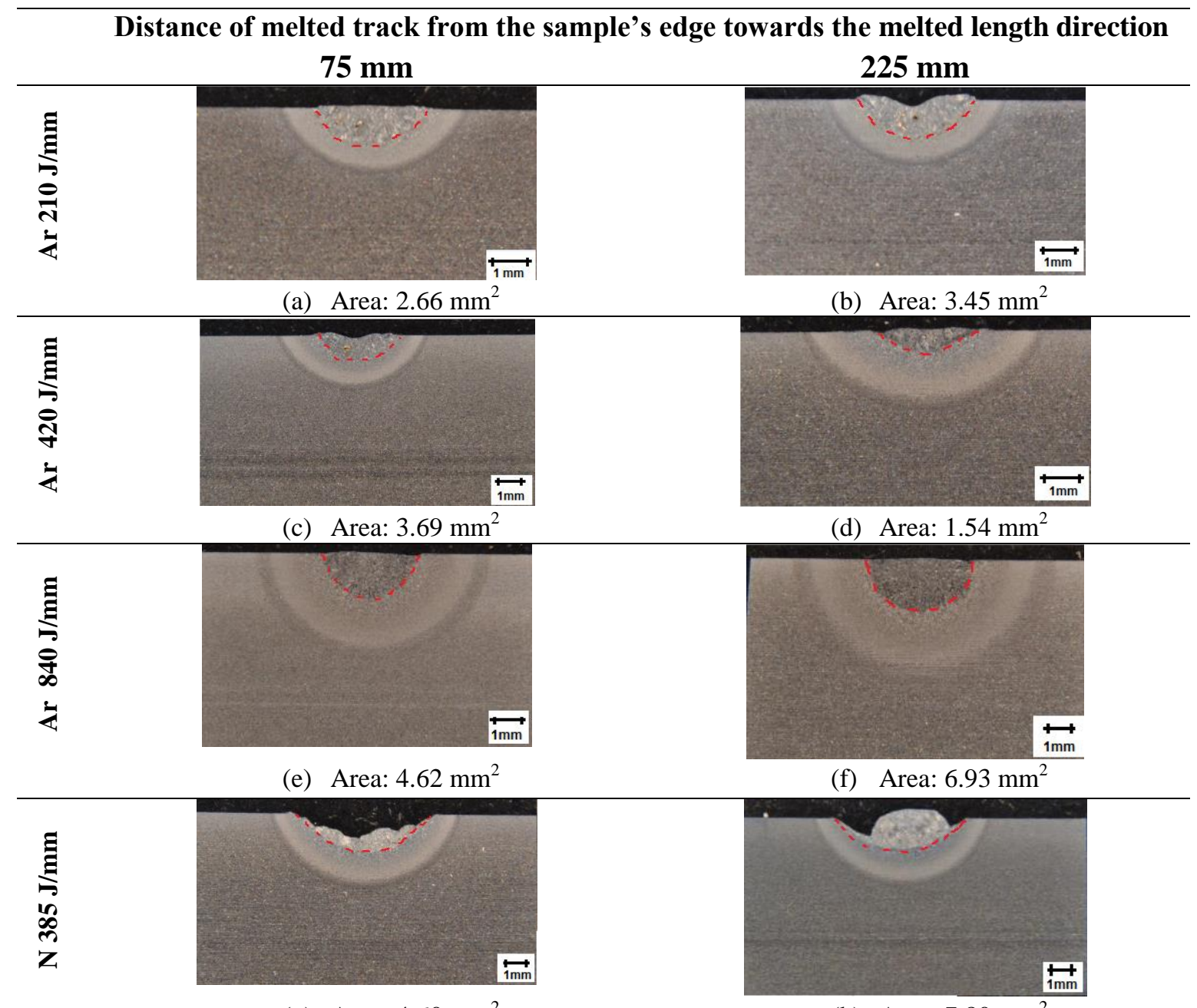

(g) Area: $4.60 \mathrm{~mm}^{2}$

(h) Area: $7.80 \mathrm{~mm}^{2}$

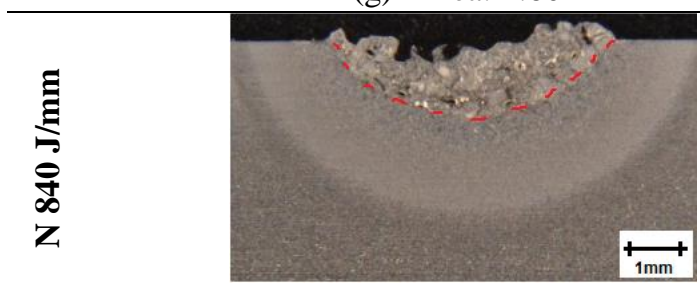

(i) Area: $9.35 \mathrm{~mm}^{2}$

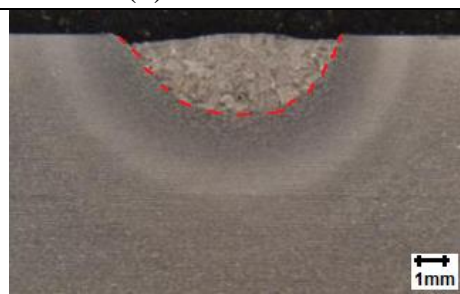

(j) Area: $16.76 \mathrm{~mm}^{2}$

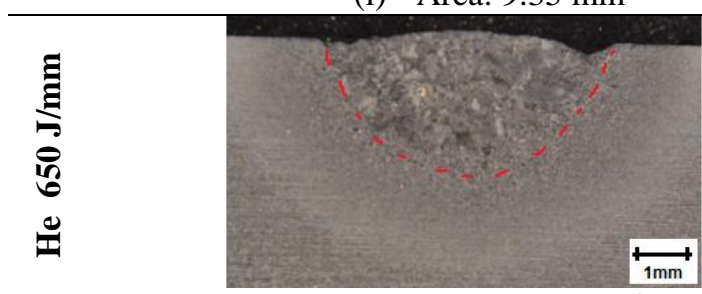

(k) Area: $11.35 \mathrm{~mm}^{2}$

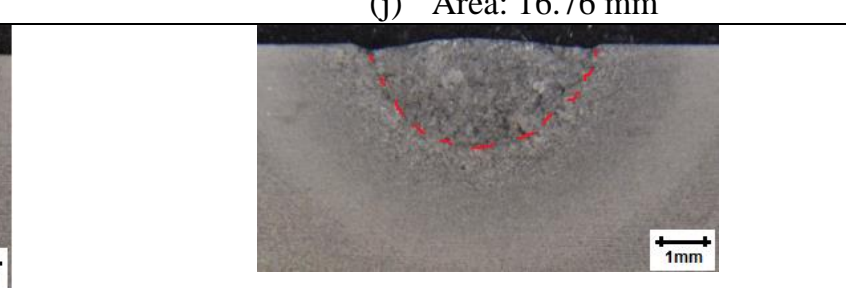

(1) Area: $14.14 \mathrm{~mm}^{2}$

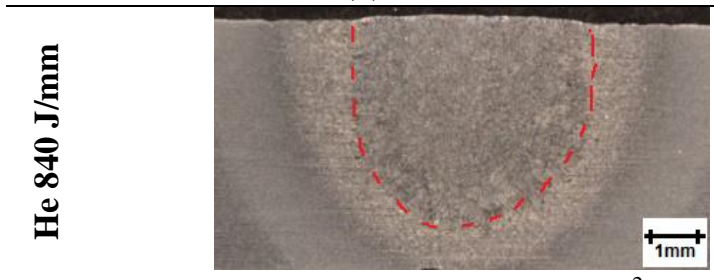

(m) Area: $22.28 \mathrm{~mm}^{2}$

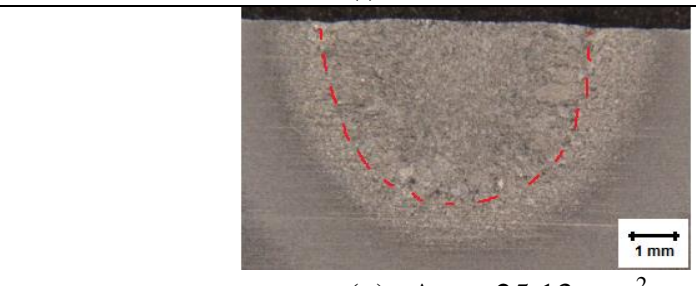

(n) Area: $25.13 \mathrm{~mm}^{2}$

Figure 7. Appearance of the melted pool cross sectional at different locations of the melted track when using shielding gases at different conditions. 
Also, it is observed that in general, the cross sectional areas increased when comparing the initial and final stage, by $\sim 32 \%$ for argon, $42 \%$ for nitrogen and $15 \%$ for helium. This change is probably due to the final section of the melted track responding to the preheat process. It was also noticed that an increase in the energy input produced an increase in the cross sectional area, an increase of $300 \%$ in energy input when using argon produced an increase of $273 \%$ of fusion cross section area, an increase of $118 \%$ of energy input when using nitrogen produced an increase of $\sim 110 \%$ of cross sectional area, and an increase of $30 \%$ of energy input when using helium produced an increase of $\sim 80 \%$ in cross sectional area. These figures indicate that helium has greater influence on the melt zone cross sectional areas when compared to argon and nitrogen.

The Vickers hardness profile resulted when using argon and nitrogen as shielding gas with different energy input is collated in Figure 8. Analysing this data, shows that in general the melted zone reached the highest hardness values, followed by the HAZ and finally the parent material, regardless of the melted conditions. Also, it is observed that the higher the energy input the smaller the hardness value of the melted zone. This result was expected as the higher the heat input the higher the temperature reached and indeed the slower the cooling process.

It is observed that when using argon as shielding gas an increase of $400 \%$ of the energy input rate (from $210 \mathrm{~J} / \mathrm{mm}$ to $840 \mathrm{~J} / \mathrm{mm}$ ) produced a decreased of hardness in the melted zone of $55 \%$, while an increase of $\sim 120 \%$ in energy input rate (from $385 \mathrm{~J} / \mathrm{mm}$ to $840 \mathrm{~J} / \mathrm{mm}$ ), when using nitrogen gas, produced a decrease of $\sim 35 \%$ in the melted. The hardness for helium was kept practically the same when using an energy input of $650 \mathrm{~J} / \mathrm{mm}$ and $840 \mathrm{~J} / \mathrm{mm}$. The data for helium is in agreement with previous research [20]. When comparing argon, nitrogen and helium at $\sim 840 \mathrm{~J} / \mathrm{mm}$, a lower hardness was obtained when using helium; this result is associated with the high ionization potential value for this gas. The data for argon and at this energy input ( $\sim 840 \mathrm{~J} / \mathrm{mm})$ was kept almost the same. 


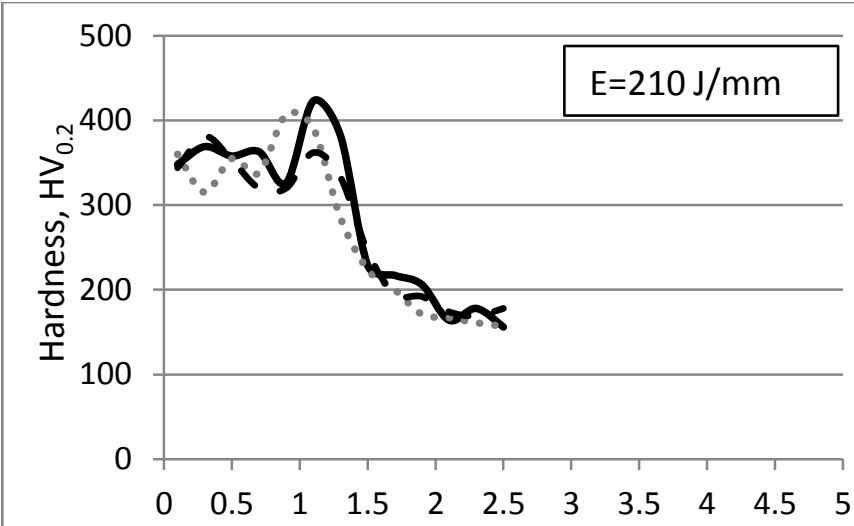

Distance from fusion zone towards parent material [mm]

$\longrightarrow 75 \mathrm{~mm} \cdots 150 \mathrm{~mm}-225 \mathrm{~mm}$

a)

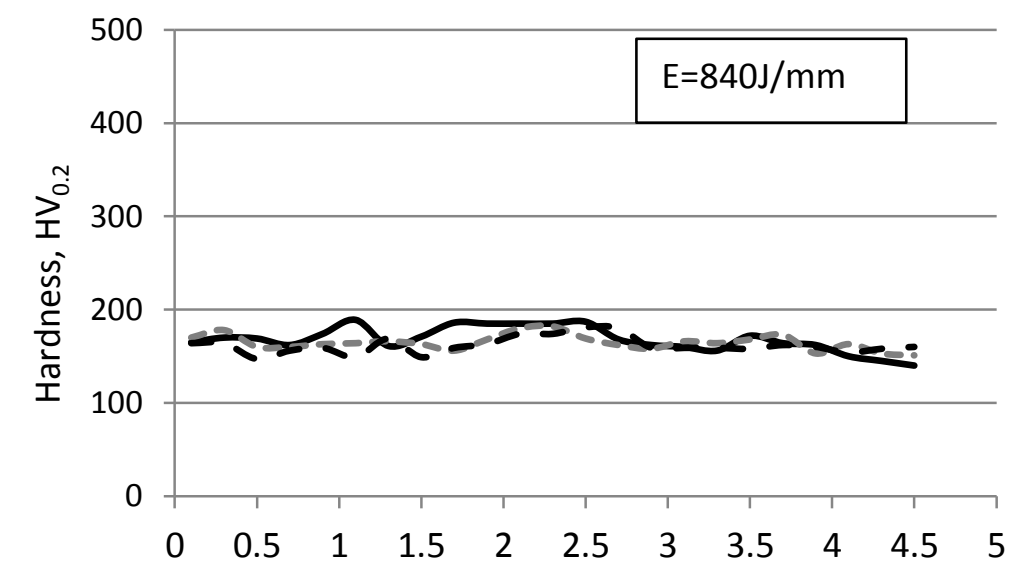

Distance from fusion zone towards parent material [mm]

$\longrightarrow 75 \mathrm{~mm}=-150 \mathrm{~mm}-225 \mathrm{~mm}$

b)

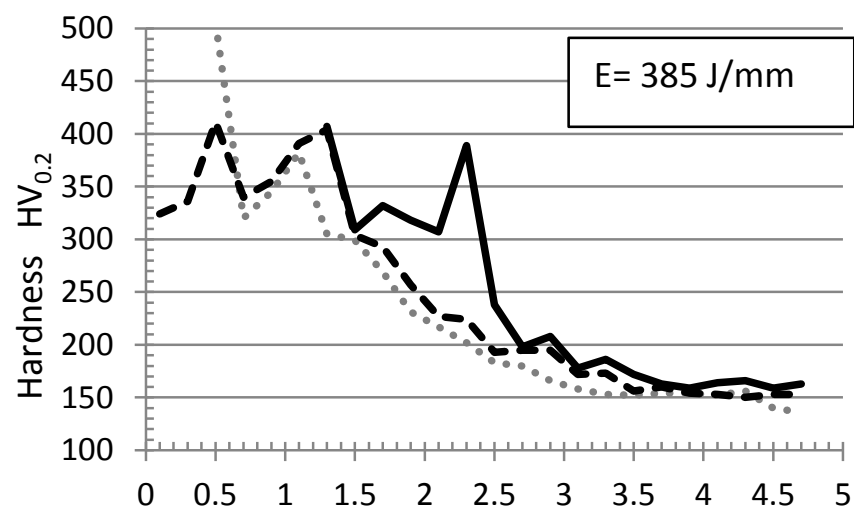

Distance from melted zone towards the parent material $(\mathrm{mm})$

$75 \mathrm{~mm}$ $150 \mathrm{~mm}$

$225 \mathrm{~mm}$

c)

Figure 8. Hardness profile for samples melted under different conditions

a) Argon, $E=210 \mathrm{~J} / \mathrm{mm}$, b) Argon $E=840 \mathrm{~J} / \mathrm{mm}$ and c) Nitrogen, $E=385 \mathrm{~J} / \mathrm{mm}$ 
The unusual cross-sections for melting under nitrogen shown in Figure 7g.h and i, have been considered in more detail in Figure 9, along with the main elements detected in the EDX spectra. The convex surface in Fig.9b has an upper 'polygonal grain' oxide layer, $\sim 37 \% \mathrm{O}$, a composition relatively close to haematite, $\mathrm{Fe}_{2} \mathrm{O}_{3}$, giving an uneven surface appearance. At the oxide-MZ interface, the $\mathrm{O}$ level decreased to $3 \%$, and the interface is smooth. The thickness of the MZ increases from the top surface to the vertical MZ-PM interface, and the SEM secondary images shown in Fig9c and Fig.9d, for both the MZ and PM, look similar, with zero $\mathrm{O}$ detected at the MZ-HAZ interface, indicated by the dashed arrow. Fig.9d is a bainitic microstructure, while Fig 8c, is similar, but contains more ferrite due to a slower rate of cooling. Similar levels of $\mathrm{O}$ were recorded for the top layer seen in Figs. 9e and 9h, while the $\mathrm{PM}$ may have an $\mathrm{O}$ content below the levels of detection. The Fe-O phase diagram, Figure 10 , compiled by Wriedt [27], shows that below $\sim 1400^{\circ} \mathrm{C}, \mathrm{O}$ is in solid solution in Fe, but at $\sim 30 \mathrm{wt} \% \mathrm{O}, \mathrm{Fe}_{2} \mathrm{O}_{3}$ forms, which is slightly below the $\mathrm{O}$ levels shown on Figs.9b, 9e and 9h. It known that the nitrogen used as a shielding contains gaseous impurities, which in the present work are influencing the upper $\sim 10 \mu \mathrm{m}$ of the fusion zone, resulting in the irregular surface found in Figs $7 \mathrm{~g}, 7 \mathrm{~h}$ and $7 \mathrm{i}$. This would be ground during any wear testing operation, exposing the alloy below, and contributing to three-body wear.

The build-up of heat resulting in the changes in shape of the MZ, between Figs.9a and Fig.9f, where in the latter, the sides, indicated by the broken arrows have wetted with the contact angle $\theta \approx 0^{\circ}$, but in the $\mathrm{MZ}$ central region where $\theta \rightarrow 90^{\circ}$, the $\mathrm{MZ}$ has globulrized, indicating little wetting. The EDX analysis showed nearly $10 \% \mathrm{Si}$ associated with the MZ. Si was not recorded in any of the other EDX spectra in this work. Fig.5 indicated a significant increase in the maximum temperature recorded by thermocouple following processing at $840 \mathrm{~J} / \mathrm{mm}$ compared with processing at $385 \mathrm{~J} / \mathrm{mm}$ with a nitrogen shielding gas.

The higher energy input resulted in the concave smooth surface observed in Fig.9i, but the hardness of the MZ is similar to that of the PM. Here, the shape of the surface and the defect -free MZ, are more important than the hardness, which will be increased in future work, by the addition of ceramic particulates. 

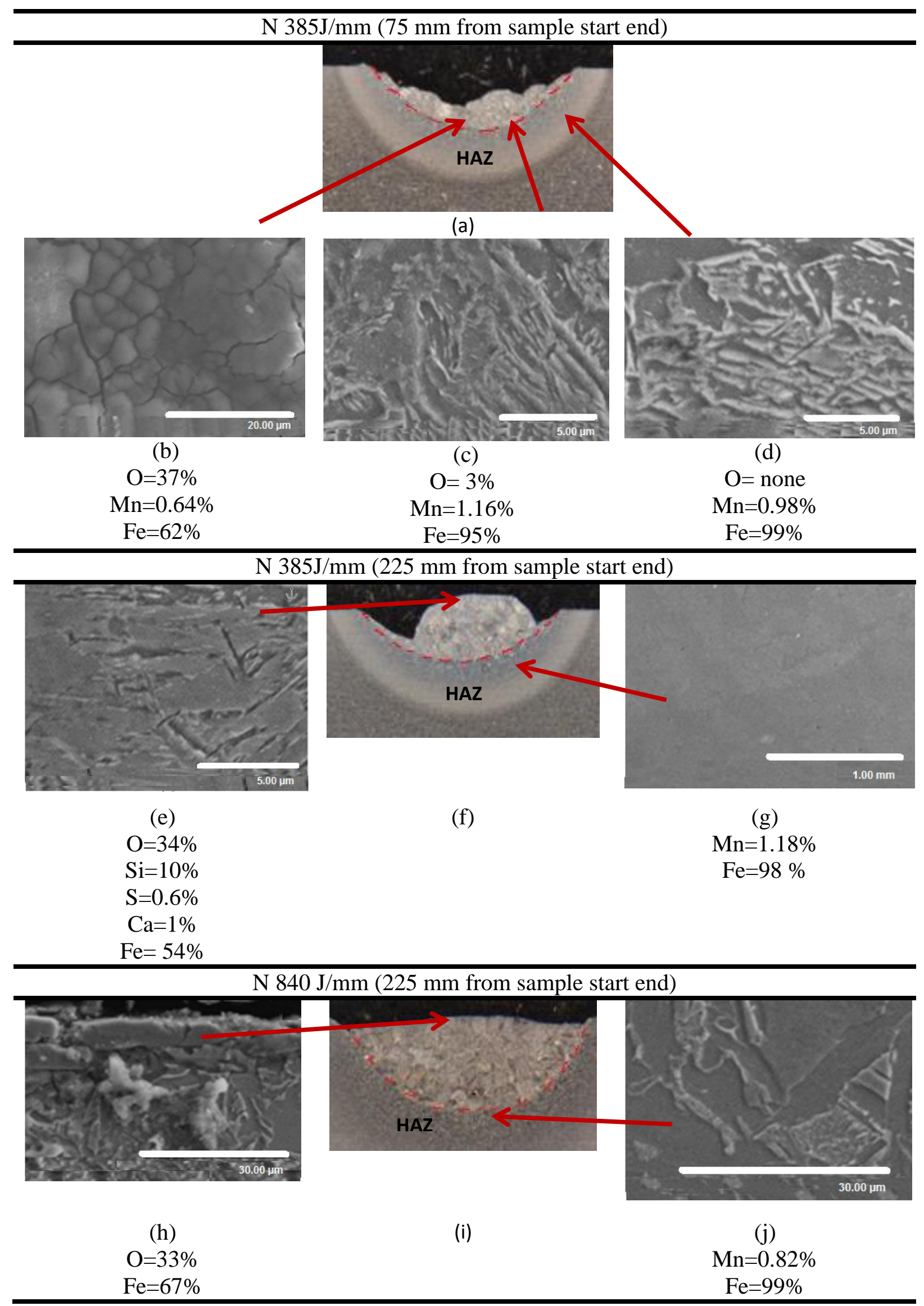

Figure 9. SEM images for samples welded with nitrogen at different energy input 


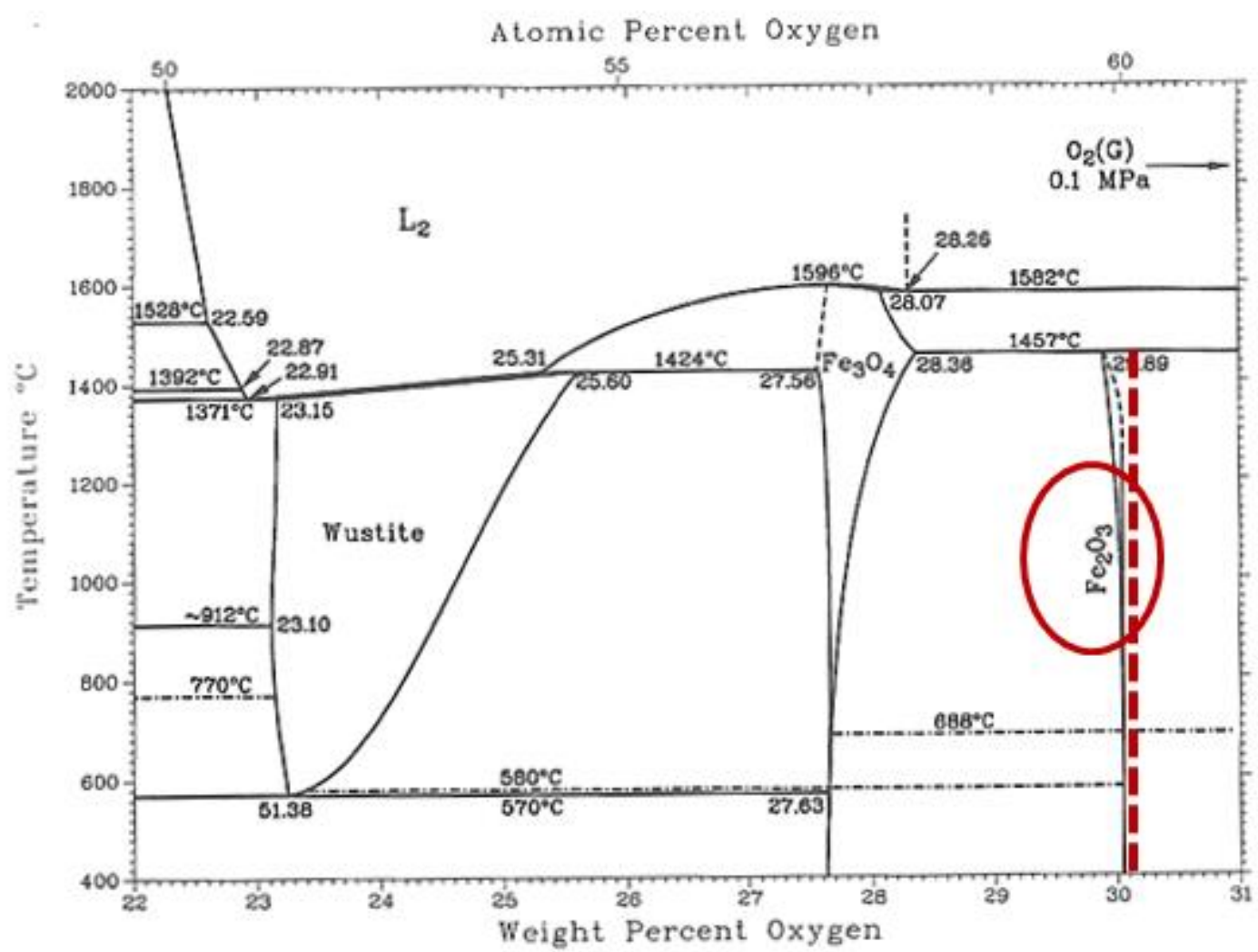

Figure 10. Fe-O phase diagram from 22-31 wt\% O (adapted from Wreidt [27])

The higher energy input of $840 \mathrm{~J} / \mathrm{mm}$, resulted in a slightly concave surface, a thin adherent oxide layer, with the MZ exhibiting excellent wetting on the steel. The influence of the wetting propensity has a direct effect on the surface roughness. This is apparent in Table 3 , which shows the surface roughness value taken at the end of the melted track $(225 \mathrm{~mm}$ from the start end).It was not possible to acquire data for $\mathrm{N} 385 \mathrm{~J} / \mathrm{mm}$ and $\mathrm{He} 650 \mathrm{~J} / \mathrm{mm}$, because the surfaces were too uneven to record Ra values.

The corresponding micrographs are also given in Table 3, which clearly show the advantage of using argon as a shielding gas, at $840 \mathrm{~J} / \mathrm{mm}$ energy input, recording an Ra of $4 \mu \mathrm{m}$, the lowest in this set of experiments. This surface would require little or no machining, prior to wear testing.

Table 3 shows the surface roughness value taken at the end of the melted track $(225 \mathrm{~mm}$ from the start end)

Table 3. Average surface roughness values obtained at $225 \mathrm{~mm}$ from start end

\begin{tabular}{|c|c|c|c|c|c|c|c|}
\hline Sample & $\underset{210 \mathrm{Jr} / \mathrm{mm}}{\operatorname{Ar}}$ & $\underset{420 \mathrm{Ar} / \mathrm{mm}}{\text { Ar }}$ & $\underset{840 \mathrm{Jr} / \mathrm{mm}}{\mathrm{Ar}}$ & $\begin{array}{c}\mathrm{N} \\
\text { 385J/mm }\end{array}$ & $\begin{array}{c}\mathrm{N} \\
840 \mathrm{~J} / \mathrm{mm}\end{array}$ & $\begin{array}{c}\text { He } \\
650 \mathrm{~J} / \mathrm{mm}\end{array}$ & $\begin{array}{c}\text { He } \\
\text { 840J/mm }\end{array}$ \\
\hline $\begin{array}{c}\mathbf{R a} \\
{[\mu \mathrm{m}]}\end{array}$ & $\begin{array}{c}8.0 \\
\text { (Fig 7b) }\end{array}$ & $\begin{array}{c}10.0 \\
\text { (Fig 7d) }\end{array}$ & $\begin{array}{c}4.0 \\
\text { (Fig 7f) }\end{array}$ & & $\begin{array}{c}25 \\
\text { (Fig 7j) }\end{array}$ & $\begin{array}{c}- \\
\text { (Fig 7l) }\end{array}$ & $\begin{array}{c}12 \\
\text { (Fig 7n) } \\
\end{array}$ \\
\hline
\end{tabular}




\section{Conclusions}

- The aim of this research has been achieved: finding the processing conditions to produce a flat melt track surface showing no signs of porosities and/or cracks within a melt zone depth $>1 \mathrm{~mm}$.

- The increased in temperature at the final stage of the melted track is considered to depend more on the type of shielding gas used rather than the welding parameters. However changes need to be greater than $200{ }^{\circ} \mathrm{C}$ to possibly result in changes to the microstructure.

- Optimal weld conditions for the microalloyed steel studied in the present work can be achieved when using values of energy input of $\sim 840 \mathrm{~J} / \mathrm{mm}$ with argon as shielding gas. This provided consistent cross-sectional area along the melted track and lower values of surface roughness.

- Experimental and theoretical cross-section geometry differ as when using helium as shielding gas a much deeper melted zone was obtained under same conditions of energy input.

\section{Acknowledgments}

The authors would like to thank Steven Black, Gerard Johnston, James Kelly and Joshua Ruston for their technical support in this work

\section{References}

[1] Cotell C, Sprague J A. 'ASM Handbook', 'Surface engineering',v,5, 1994,Materials Park, $\mathrm{OH}, \mathrm{ASM}$ International.

[2] Ayers J D, Schaefer R J. Proc. conf. 'Laser applications in material processes', (J. F. Ready ed.), 57- 64, 198, 1979, Bellingham, SPIE.

[3] Fasasi A Y, Pons M, Tassin C, Galerie A, Sainfort G, Polak C J. Mater. Sci, 1994, 29, 5121-5126.

[4] Selamat M S, Watson L.M, Baker T N. J. Mater Proc.Technol.2003,142,725-737.

[5] Baker T N. In Surface engineering of light alloys; aluminium, magnesium and titanium alloys, [ed.H.Dong] 398-443,2010, Woodhead Publishing, Oxford, UK.

[6] Weng F, Chen C Z, Yu H J. Mater. Design, 2014, 58, 412-425.

[7] Atamert S, Bhadeshia HKDH. Comparison of the microstructures and abrasive wear properties of stellite hardfacing alloys deposited by arc-welding and laser cladding. Metall.Trans.A, 1989,20, 1037-1054.

[8] Mridha S, Ho SY, Kum S T. Surface Layer Addition of Hard Particles using TIG Arc MeltingConf.proc, 'Processing and Fabrication of Advanced 
MaterialsVI' (K.A. Khor, T.S. Srivatsan and J.J. Moore, eds.)1331-1338, 1998, Singapore.

[9] Mridha S, Dyutti S. Formation of TiN Dispersed Composite Layer on Steel Surfaces by Titanium Powder Preplacement and TIG Surface Melting ProcessesAdv.Mater.Res.2011, 264-265, 1415-1420.

[10] Wang X H, Song S L, Zou Z D. Fabricating TiC particles reinforced Fe-based composite coatings produced by GTAW multilayers melting process. Mater.Sci.Eng., 2006,441,6067.

[11] Lyttle KA. Shielding Gases. ASM Handbook Welding, Brazing and Soldering.1993, 6, 64-69.

[12] Walker A, Foulkes J, Steen W M, West DRF. Laser surface alloying of titanium substrate with carbon and nitrogen. Surf. Eng, 1985, 1, 23-29.

[13] Xin H, Watson L M, Baker T N. Surface analytical studies of a laser nitrided Ti-6Al-4V alloy: A comparison of spinning and stationary laser beam modes. Acta Mater. 1998, 46, 1949-1961.

[14] Hoeche D, Schaaf P. Laser nitriding: investigations on the model system TiN. A review.Heat Mass Transfer,2011,47,519-540.

[15] Mridha S, Baker T N. Metal matrix composite layer formation with $3 \mathrm{mu}$ m SiCp powder on IMI318 titanium alloy surfaces through laser treatmentJ.Mater.Proc.Technol.,1997,63,432-437.

[16] Chen Y B, Liu D J, Li F Q, Li L Q, WCp/Ti-6Al-4V graded metal matrix composites layer produced by laser melt injection.Surf.Coat.Technol.,2008,202,4780-4787.

[17] Kooi B J, Pei Y T and De Hosson J T M. The evolution of microstructure in a laser clad TiB-Ti composite coatingActa Mater.,2003,51,831-845.

[18] Wang X H, Song S L, Qu S Y, Zou S D. Characterization of in situ synthesized TiC particle reinforced Fe-based composite coatings produced by multi-pass overlapping GTAW melting process. Surf.Coat.Technol.,2007,201,5899=5905.

[19] Mridha S, Idriss A N Md, Baker T N. Incorporation of TiC particles on AISI 4340 low alloy steel surfaces via tungsten inert gas arc meltingAdv.Mater.Res.,2012,445,655-660.

[20] Ulutan M, Yildirim M M, Buytoz S, Celik O N. Microstructure and Wear Behavior of TIG Surface-Alloyed AISI 4140 Steel. Tribo. Trans, 2011, 54, 67-79.

[21] Hu C, Baker T N. J. Overlapping laser tracks to produce a continuous nitrided layer in Ti-6Al-4V alloy. Mater.Sci., 1997, 32, 2821-2826. 
[22] Patel P, Mridha S, Baker T N. Influence of shielding gases on preheat produced in surface coatings incorporating $\mathrm{SiC}$ particulates into microalloy steel using TIG technique. Mater. Sci. Technol.,2014, 30,1506-1514.

[23] Muñoz-Escalona P, Mridha S, Baker T N. Effect of Silicon Carbide Particle Size on Microstructure and Properties of a Coating Layer on Steel Produced by TIG Technique. Adv. Mater. Proc. Technol., 2015, 1, 435-443.

[24 Easterling K E. Introduction to the physical metallurgy of welding. London: Butterworth- Heinemann;1992.

[25] DuPont J N, Marder A R. Thermal efficiency of arc-welding processes. Welding J., 1995, 74, 406s-416s.

[26] Thawari G, Sundarararjan G, Joshi S V. Laser surface alloying of medium carbon steel with $\operatorname{SiC}(\mathrm{P})$. Thin Solid Films, 2003, 423,41-53.

[27] Wriedt H A ,ASM handbook', 'Alloy phase diagrams', 2-199, 3; 1992, Materials Park, $\mathrm{OH}, \mathrm{ASM}$ International. 